\title{
Primed Stimulation of Isolated Perfused Rabbit Lung by Endotoxin and Platelet Activating Factor Induces Enhanced Production of Thromboxane and Lung Injury
}

William L. Salzer and Charles E. McCall

Section of Infectious Diseases, Department of Medicine, Bowman Gray School of Medicine of Wake Forest University, Winston-Salem, North Carolina 27103

\begin{abstract}
Bacterial sepsis often precedes the development of the adult respiratory distress syndrome (ARDS) and bacterial endotoxin (LPS) produces a syndrome similar to ARDS when infused into experimental animals. We determined in isolated, bufferperfused rabbit lungs, free of plasma and circulating blood cells that LPS synergized with platelet activating factor (PAF) to injure the lung. In lungs perfused for $2 \mathrm{~h}$ with LPS-free buffer $(<100 \mathrm{pg} / \mathrm{ml})$, stimulation with 1,10 , or $100 \mathrm{nM}$ PAF produced transient pulmonary hypertension and minimal edema. Lungs perfused for 2 h with buffer containing 100 $\mathrm{ng} / \mathrm{ml}$ of Escherichia coli 0111:B4 LPS had slight elevation of pulmonary artery pressure (PAP) and did not develop edema. In contrast, lungs exposed to $100 \mathrm{ng} / \mathrm{ml}$ of LPS for $2 \mathrm{~h}$ had marked increases in PAP and developed significant edema when stimulated with PAF. LPS treatment increased capillary filtration coefficient, suggesting that capillary leak contributed to pulmonary edema. LPS-primed, PAF-stimulated lungs had enhanced production of thromboxane $B_{2}$ (TXB) and 6-ketoprostaglandin $F 1$ alpha (6KPF). Indomethacin completely inhibited PAF-stimulated production of TXB and 6KPF in control and LPS-primed preparations, did not inhibit the rise in PAP produced by PAF in control lungs, but blocked the exaggerated rise in PAP and edema seen in LPS-primed, PAFstimulated lungs. The thromboxane synthetase inhibitor dazoxiben, and the thromboxane receptor antagonist, SQ 29,548, similarly inhibited LPS-primed pulmonary hypertension and edema after PAF-stimulation. These studies indicate that LPS primes the lung for enhanced injury in response to the physiologic mediator PAF by amplifying the synthesis and release of thromboxane in lung tissue. (J. Clin. Invest. 1990. 85:11351143.) endotoxin • thromboxane • platelet activating factor • adult respiratory distress priming syndrome

\section{Introduction}

Acute lung injury occurring in association with the adult respiratory distress syndrome (ARDS) ${ }^{1}$ appears to result from an

Presented in part at the National Meeting of the American Federation of Clinical Research, 1-4 May 1987, San Diego, CA, and published in abstract form in 1987 (Clin. Res. 35:538a).

Address reprint requests to Dr. Salzer, Department of Medicine, Bowman Gray School of Medicine, 300 South Hawthorne Road, Winston-Salem, NC 27103.

Received for publication 21 July 1988 and in revised form 5 September 1989.

1. Abbreviations used in this paper: ARDS, adult respiratory distress syndrome; IPL, isolated perfused lung; $K_{f, c}$, capillary filtration coeffi-

J. Clin. Invest.

(C) The American Society for Clinical Investigation, Inc. 0021-9738/90/04/1135/09 \$2.00

Volume 85, April 1990, 1135-1143 inflammatory reaction in the lung. Pulmonary capillaries are occluded with aggregates of polymorphonuclear leukocytes $(P M N)$ and platelet-fibrin thrombi (1). The end result of this local inflammatory process is damage to the endothelium of the pulmonary capillaries with leakage of plasma and cellular elements of blood across a normally impermeable barrier into the interstitial and alveolar spaces of the lung. Physiologically this injury is associated with pulmonary arterial hypertension along with ventilation-perfusion mismatching, and severely impaired gas exchange in the lung (2). Inflammatory mediators derived from plasma through activation of the complement and coagulation cascades as well as lipid mediators, protein cytokines, proteolytic enzymes, and reactive species of oxygen released by leukocytes and platelets in the circulation and resident inflammatory cells in the lung are thought to be responsible for this injury (3). Release of these mediators may initiate a self-perpetuating chain reaction through recruitment of circulating leukocytes and platelets to the lung and by stimulating the production of additional inflammatory mediators by effector cells in the lung. It is likely that multiple inflammatory mediators and cell types acting synergistically are necessary to produce the degree of injury found in the lungs of patients with ARDS.

In inflammatory shock syndromes like ARDS, complex interactions between multiple cell types and mediators occur. Attempts to implicate a single causative event, for example complement activation (4), as the sole factor responsible for these forms of injury have been unsuccessful. We and others have shown that soluble mediators are capable of interacting synergistically to amplify potentially injurious inflammatory responses (5). In vitro experiments demonstrate that stimuli in submaximal or even ineffective concentrations are able to "prime" inflammatory cells for an enhanced response to a second stimulus (6). On a subcellular level, priming is thought to be mediated through the interaction of stimulus-response coupling mechanisms such as the G-proteins, cyclic nucleotides, intracellular calcium levels, activation of phospholipases, and activation of protein kinases (7). A similar sequence of events may occur in vivo to amplify the response of inflammatory cells to small concentrations of stimulatory mediators. The explosive shock-like injury of sequential, nonlethal doses of endotoxin in the Shwartzman reaction suggests this possibility.

Bacterial sepsis, in particular infection with gram negative bacilli, commonly precedes the development of ARDS (8). Endotoxin (LPS), the lipopolysaccharide present in the outer cell membrane of gram negative organisms, reproduces the pathophysiologic manifestations of sepsis when administered

cient; 6KPF, 6-keto-prostaglandin- $F_{1 \text { alpha }}$; LPS, lipopolysaccharide; PAF, platelet activating factor; PAP, pulmonary artery pressure; PLA $_{2}$, phospholipase $\mathrm{A}_{2}$; TNF- $\alpha$, tumor necrosis factor- $\alpha$; TXA, thromboxane $A_{2} ;$ TXB, thromboxane $B_{2}$. 
parenterally (9), and in some species induces acute lung injury resembling ARDS in humans (10). These adverse effects appear to result from the activation of inflammatory cells and the production of secondary mediators rather than through direct cellular toxicity of LPS (9).

In animal models of sepsis and septic lung injury the lipid agonists platelet activating factor (PAF) and thromboxane $A_{2}$ (TXA) may be important mediators of injury. These autocoids are produced from membrane phospholipids upon cellular activation $(11,12)$. Inhibitors of cyclooxygenase or thromboxane synthetase ameliorate pulmonary hypertension and edema in the early phases of LPS-induced lung injury in experimental animals (10). PAF antagonists, which block PAF receptors, markedly inhibit LPS-induced hypotension and reduce lung injury in rats receiving LPS (13). These findings suggest that TXA and PAF may act as distal mediators (i.e., directly injure tissues) in the sequence of events induced by LPS.

The isolated perfused rabbit lung (IPL) provides a model to investigate the pathogenesis of acute pulmonary injury (14). The buffer perfused IPL is virtually free of plasma proteins and cellular elements of blood, allowing manipulation of the system to study the effects of individual circulating cell types and mediators within the lung. In the present study we used the IPL to test the hypothesis that LPS would prime the lung for enhanced responses to PAF. While LPS produced little change in pulmonary artery pressure and no edema by itself, and PAF alone produced only mild pulmonary hypertension without edema, LPS primed the lung for marked elevation of pulmonary artery pressure and edema upon stimulation with PAF. Capillary permeability was increased in LPS treated lungs. The LPS-primed injury was associated with accentuated release of TXB and prostacyclin. The cyclooxygenase inhibitor indomethacin, as well as the thromboxane synthetase inhibitor dazoxiben, and the thromboxane receptor antagonist SQ 29,548 completely inhibited the primed-stimulation response. These findings indicate that LPS primes the lung for enhanced injury in response to an endogenous inflammatory mediator. The pulmonary hypertension in the early phases of septic lung injury may occur through LPS-primed, amplified release of TXA in response to mediators, which in the absence of LPS are relatively benign.

\section{Methods}

\section{Materials}

Gentamicin sulfate, indomethacin, papaverine, E-TOXATE, and ETOXACLEAN were obtained from Sigma Chemical Corp., St. Louis, MO. E. coli 0111: B4 endotoxin was purchased from DIFCO Laboratories, Detroit, MI. Sterile, pyrogen-free, lactated Ringer's solution for injection was produced by Kendall-McGaw Laboratories, Irvine, CA. Ketamine $\mathrm{HCl}$ was from Parke-Davis Co., Morris Plains, $\mathrm{NJ}$; xylazine $\mathrm{HCl}$ from the Butler Co., Columbus, $\mathrm{OH}$. Succinylcholine $\mathrm{Cl}$ was from Abbott Laboratories, North Chicago, IL; heparin sodium from beef lung was obtained from The Upjohn Co., Kalamazoo, MI. Sterile pyrogen-free human serum albumin (Albuminar-25) was produced by Armour Pharmaceuticals Co., Kankakee, IL. Dazoxiben $\mathrm{HCl}$ was a gift from Pfizer Central Research, Kent, England. SQ 29,548 was a gift from E. R. Squibb \& Sons, Princeton, NJ. PAF (1-O-hexadecyl-2-acetyl-sn-glycero-3-phosphorylcholine) was synthesized by Dr. Robert Wykle of the Bowman Gray School of Medicine using previously described methods (15) and stored in chloroform/methanol at $-70^{\circ} \mathrm{C}$ under nitrogen.

\section{Isolated perfused lung (IPL) preparation}

New Zealand white rabbits weighing $\sim 3 \mathrm{~kg}$ were purchased from Franklin's Rabbitry, Raleigh, NC. The animals were anesthetized with an intramuscular injection of $20 \mathrm{mg}$ of xylazine and $100 \mathrm{mg}$ of ketamine and received supplemental intravenous ketamine to maintain a comatose state with spontaneous respirations. Tracheostomy was performed, the animal was paralyzed with $20 \mathrm{mg}$ i.v. of succinylcholine and the lungs were ventilated for the remainder of the experiment using a small animal respirator (model 683; Harvard Apparatus Co., Millis, MA). The heart and lungs were exposed with a midline sternotomy and $500 \mathrm{U}$ of heparin were injected into the right ventricle. The pulmonary circulation was cannulated and perfused with catheters inserted into the pulmonary artery via the right ventricle and left atrium through the left ventricle. The heart and lungs were removed from the thoracic cavity and suspended. The pulmonary circulation was perfused with lactated Ringer's solution containing $25 \mathrm{mg} / \mathrm{liter}$ of gentamicin. Initially, $700 \mathrm{ml}$ of buffer was perfused through the system and discarded to remove the plasma and circulating blood cells from the pulmonary circulation. After this $700-\mathrm{ml}$ washout a recirculating system was established with $300 \mathrm{ml}$ of buffer at a constant flow of 125 $\mathrm{ml} / \mathrm{min}$ through a reservoir thermostated to maintain the perfusate at $37-39^{\circ} \mathrm{C}$ for the duration of the experiment. The initial $700-\mathrm{ml}$ washout effectively removed the animal's plasma and blood cells from the pulmonary circulation. The recirculating buffer contained 50-250 red blood cells $/ \mathrm{mm}^{3}, 1-2$ white blood cells $/ \mathrm{mm}^{3}$, and no detectable platelets.

\section{Measurements}

Pulmonary arterial and venous pressures were monitored using Gould-Statham model P23 pressure transducers (Statham Instruments, Hato Rey, PR). The pulmonary venous pressure was set to 0 at the beginning of each experiment by adjusting the height of the recirculating reservoir to that of that of the left atrium. Weight gain by the lung was monitored by suspending the preparation from a force displacement transducer (model FT03; Grass Instruments, Quincy, MA) balanced to 0 at the start of each experiment. Pressure and weight gain were recorded continuously on a Grass model 7 polygraph. In control experiments perfused with buffer alone the IPL was stable over $3.5 \mathrm{~h}$ without changes in pulmonary artery pressure and minimal weight gain of $0-5 \mathrm{~g}$.

\section{Maintenance of endotoxin-free conditions}

Endotoxin content of the perfusate in these experiments were measured using the limulus lysate assay (E-TOXATE; Sigma Chemical Co.). We were able to maintain the perfusate essentially endotoxin-free $(<100 \mathrm{pg} / \mathrm{ml})$ for the duration of the experiment $(3 \mathrm{~h})$. The perfusion buffer was pyrogen-free, sterile, lactated Ringer's solution for injection. Gentamicin sulfate, $25 \mathrm{mg} /$ liter, was added to the buffer to prevent bacterial growth during the experiment. All disposable equipment used in the perfusion circuit was sterile and pyrogen free. Nondisposable equipment was washed in laboratory detergent, washed in E-TOXACLEAN, and rinsed with endotoxin-free deionized water before reuse. In occasional experiments endotoxin concentrations in the perfusate exceeded $100 \mathrm{pg} / \mathrm{ml}$. Results from these experiments were not included for data analysis.

\section{Experimental design}

The isolated perfused lung was prepared as described above. The lungs were perfused for $15 \mathrm{~min}$ after the reperfusion circuit was established before any experimental manipulations to ensure that the preparation was stable.

$P A F$ alone. In lungs receiving PAF alone, the IPL was perfused with endotoxin-free buffer for $2 \mathrm{~h}$ with samples of the perfusate removed at 0,60 , and $120 \mathrm{~min}$ for endotoxin determinations. Immediately before use, PAF was dried under a stream of nitrogen to remove the organic solvent and was resuspended in buffer containing $2.5 \mathrm{mg} / \mathrm{ml}$ of sterile pyrogen-free human serum albumin. PAF was added to the IPL in 
amounts resulting in concentrations of $1 \mathrm{nM}(0.157 \mu \mathrm{g}), 10 \mathrm{nM}(1.57$ $\mu \mathrm{g})$, and $100 \mathrm{nM}(15.7 \mu \mathrm{g})$ in the $300-\mathrm{ml}$ perfusion bath. The compound was administered at $2 \mathrm{~h}$ by bolus injection into an injection port just proximal to the pulmonary artery cannula. The IPL was monitored for $1 \mathrm{~h}$ after PAF was given.

LPS and PAF. $30 \mu \mathrm{g}$ of E. coli 0111:B4 LPS suspended in 0.9\% sterile saline was added to the perfusion bath at time 0 , exposing the lung to an LPS concentration of $100 \mathrm{ng} / \mathrm{ml}$. The lungs were perfused for $2 \mathrm{~h}$ with this LPS-containing buffer, then stimulated with PAF as described above and monitored for an additional hour or until the lung had gained $40 \mathrm{~g}$ of weight.

Indomethacin treatment. Stock solutions of indomethacin were prepared in DMSO at a concentration of $0.1 \mathrm{M} .30 \mu \mathrm{l}$ was added to the perfusion bath at the end of the 15-min warm-up period resulting in a concentration of $10 \mu \mathrm{M}$ in the perfusate. In LPS-treated experiments endotoxin was added $15 \mathrm{~min}$ after indomethacin, and PAF $2 \mathrm{~h}$ later or in $2 \mathrm{~h}$ and $15 \mathrm{~min}$ in LPS-free experiments.

Dazoxiben and $S Q 29,548$ treatment. The thromboxane synthetase inhibitor, dazoxiben, or the thromboxane receptor antagonist SQ 29,548 were administered through the pulmonary artery cannula 5 min before PAF stimulation in amounts yielding concentrations in the perfusate of 5 and $1 \mu \mathrm{M}$, respectively.

\section{Determination of capillary filtration coefficient $\left(K_{f, c}\right)$}

$K_{\mathrm{f}, \mathrm{c}}$ was determined according to the method of Seeger et al. (16) by measuring the rate of weight gain by the lung after a venous pressure challenge of $5 \mathrm{mmHg}$. PAF-induced pulmonary hypertension was blocked by adding $0.03 \mathrm{mg} / \mathrm{ml}$ of papaverine, a potent vasodilator, to the perfusion bath to eliminate weight gain resulting from increased capillary hydrostatic pressure. This concentration of papaverine prevented the rise in PAP under all conditions. Papaverine was added at 110 min to all lungs in which $K_{f, c}$ was measured. Lungs were treated as described above for PAF alone and LPS-PAF. At $125 \mathrm{~min}$ the venous outflow was occluded to elevate venous pressure to $5 \mathrm{mmHg}$ while the
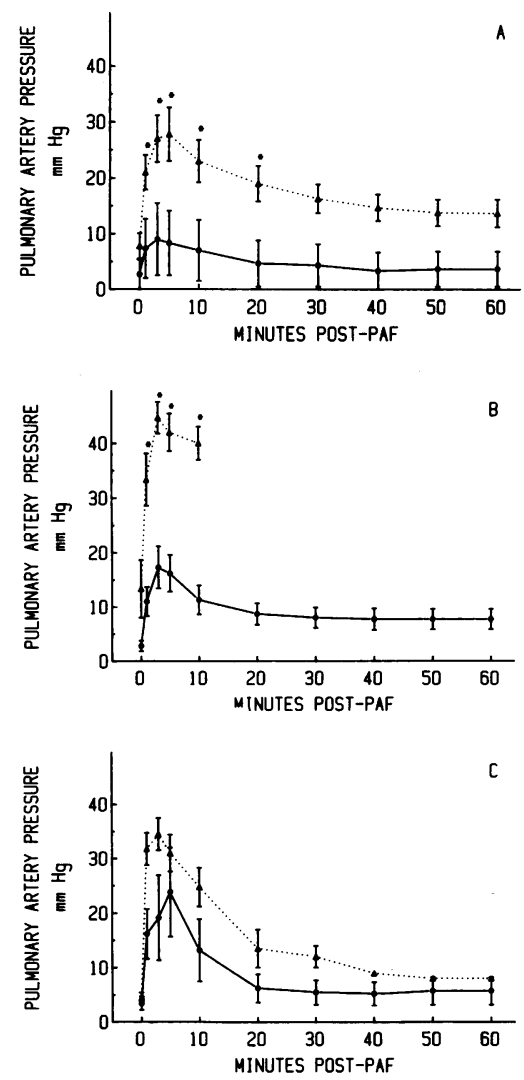

Figure 1. Effect of endotoxin on PAF-induced pulmonary hypertension. Isolated rabbit lungs were perfused with LPS-free buffer $(-\bullet-)$ or buffer containing $100 \mathrm{ng} / \mathrm{ml}$ of LPS $(\cdots . \cdots)$ for $2 h$ and received PAF $1 \mathrm{nM}$ $(A), 10 \mathrm{nM}(B)$, or 100 $\mathrm{nM}(C)$ at time 0 . Each point represents mean \pm SEM of at least three experiments. ${ }^{*} P$ $<0.05$. perfusate flow was maintained at $125 \mathrm{ml} / \mathrm{min}$. This resulted in an immediate small increment in lung weight due to increased vascular filling, followed by a gradual increase in lung weight, which represents capillary leak. The rate of weight gain was measured at $128-130 \mathrm{~min}$ (3-5 min after PAF). $K_{\mathrm{f}, \mathrm{c}}$ was calculated using the formula: $K_{\mathrm{f}, \mathrm{c}}$ $=$ weight change $(\mathrm{g}) / \mathrm{time}(\mathrm{s}) \times 5 \mathrm{mmHg} \times$ wet lung weight $(\mathrm{g}) \times 10^{-4}$. Wet lung weight was not directly measured but was calculated based on the animal's body weight (16): wet lung weight $=0.0024 \times$ body wt in $\mathrm{g}$.

Measurement of arachidonic acid metabolites. The stable metabolites of TXA, TXB, and prostacyclin, 6-keto-prostaglandin- $\mathrm{F}_{1-\text { al pha }}$ (6KPF) were measured in the perfusate of the IPL. Samples of the perfusate were removed from the perfusion bath immediately before PAF administration and 3, 5, 10, 15, 20, and 30 min after PAF. These samples were immediately centrifuged at $13,000 \mathrm{rpm}$ for $30 \mathrm{~s}$ in a Beckman Microfuge B (Beckman Instruments, Palo Alto, CA) and the supernatant fluid was frozen for prostaglandin assay. TXB and 6-KPF were measured by radioimmunoassay using kits obtained from Amersham Corp. (Arlington Heights, IL). Using 0.1-ml samples these assays have a lower level of sensitivity of $50 \mathrm{pg} / \mathrm{ml}$ for TXB and $140 \mathrm{pg} / \mathrm{ml}$ for 6-KPF.

\section{Statistics}

Data were expressed as mean \pm standard error of the mean (SEM). Data were subjected to one-way or two-way analysis of variance (ANOVA), followed by Duncan's New Multiple Range Test to determine differences between means. $P$ values of $<0.05$ were considered significantly different. Statistical analyses were performed using the Number Cruncher Statistical System, version 4.21 (J. L. Hintze, Kaysville, UT).

\section{Results}

\section{Effects of LPS alone}

LPS alone produced no immediate change in pulmonary artery pressure (PAP) or lung weight and very little change during the subsequent 2-h perfusion. After $2 \mathrm{~h}$ of perfusion with buffer containing $100 \mathrm{ng} / \mathrm{ml}$ of LPS, lungs gained a mean of $5.4 \pm 1.2 \mathrm{~g}$ compared with $5.1 \pm 1.5 \mathrm{~g}$ in lungs perfused with endotoxin-free buffer for the same length of time. At $2 \mathrm{~h}$, PAP was slightly higher in LPS exposed lungs $(7.6 \pm 1.4 \mathrm{mmHg})$ than those perfused with LPS-free buffer $(3.2 \pm 0.7 \mathrm{mmHg})$. These findings indicate that $100 \mathrm{ng} / \mathrm{ml}$ of LPS has minimal effects in the buffer perfused IPL.

\section{Effects of PAF alone}

PAF produced an abrupt increase in PAP in lungs perfused for $2 \mathrm{~h}$ under LPS-free conditions (Fig. 1). PAP began to rise within $30 \mathrm{~s}$ of PAF administration, reached its maximal level by $3 \mathrm{~min}$, and then declined toward baseline levels. The peak PAP was dose dependent, attaining means of $9 \pm 6 \mathrm{mmHg}$, $17 \pm 4 \mathrm{mmHg}$ and $25 \pm 8 \mathrm{mmHg}$ for PAF concentrations of 1 , 10 , and $100 \mathrm{nM}$, respectively (Table I).

In lungs perfused with LPS-free buffer, PAF treatment induced minimal weight gain (Fig. 2). Of six lungs given $100 \mathrm{nM}$ PAF alone, two reached $40 \mathrm{~g}$ of weight gain and the mean weight gain for the group was $12 \pm 5 \mathrm{~g}$ in the hour after PAF administration. There was minimal weight gain in the $60 \mathrm{~min}$ after treatment with $1 \mathrm{nM}(2 \pm 1 \mathrm{~g})$ or $10 \mathrm{nM}(10 \pm 5 \mathrm{~g})$ PAF alone, with none of these lungs attaining $40 \mathrm{~g}$ weight gain. In the absence of LPS, PAF induced mild, transient pulmonary hypertension, with little weight gain in the IPL.

\section{Endotoxin priming of $P A F$-induced responses}

In contrast to the mild changes in the IPL produced by PAF or LPS alone, the combination of these stimuli resulted in dra- 
Table I. Peak Pulmonary Artery Pressure and Weight Gain after PAF Administration

\begin{tabular}{|c|c|c|c|c|c|c|}
\hline \multirow[t]{2}{*}{ PAF } & \multicolumn{2}{|c|}{$1 \mathrm{nM}$} & \multicolumn{2}{|c|}{$10 \mathrm{nM}$} & \multicolumn{2}{|c|}{$100 \mathrm{nM}$} \\
\hline & - LPS & + LPS & - LPS & + LPS & - LPS & + LPS \\
\hline Peak PAP $(\mathrm{mmHg})$ & $9 \pm 6$ & $29 \pm 5^{*}$ & $17 \pm 4$ & $44 \pm 3^{*}$ & $25 \pm 8$ & $35 \pm 3$ \\
\hline Weight gain (g) & $2 \pm 1$ & $27 \pm 4^{*}$ & $10 \pm 5$ & $34 \pm 2^{*}$ & $12 \pm 5$ & $31 \pm 7^{*}$ \\
\hline
\end{tabular}

Lungs were perfused for $2 \mathrm{~h}$ with endotoxin-free buffer (-LPS) or buffer containing $100 \mathrm{ng} / \mathrm{ml}$ of $E$. coli 0111:B4 endotoxin (+LPS) then stimulated with PAF. Values are mean \pm SEM.

${ }^{*} P<0.05$ for - LPS vs. +LPS.

matic increases in PAP and lung weight. Pretreatment with $100 \mathrm{ng} / \mathrm{ml}$ of LPS for $2 \mathrm{~h}$ enhanced the rise in PAP produced by PAF (Fig. 1). The peak PAP in response to $1 \mathrm{nM}(29 \pm 5$ $\mathrm{mmHg})$ and $10 \mathrm{nM}$ PAF $(44 \pm 3 \mathrm{mmHg})$ was significantly greater in LPS-primed lungs compared with lungs treated with LPS-free buffer receiving the same amount of PAF. In LPSpretreated lungs, $100 \mathrm{nM}$ PAF also induced higher peak PAP $(35 \pm 3 \mathrm{mmHg}$ ) than with $100 \mathrm{nM}$ PAF alone but this difference was not statistically significant. Although the mean peak PAP in LPS-primed lungs was greater in lungs receiving $10 \mathrm{nM}$ PAF than $100 \mathrm{nM}$ PAF this difference was also not significant. This discrepancy in the dose-response relationship for PAF could possibly be due to the reported vasodilatory effects of PAF under conditions of intense vasoconstriction (17).
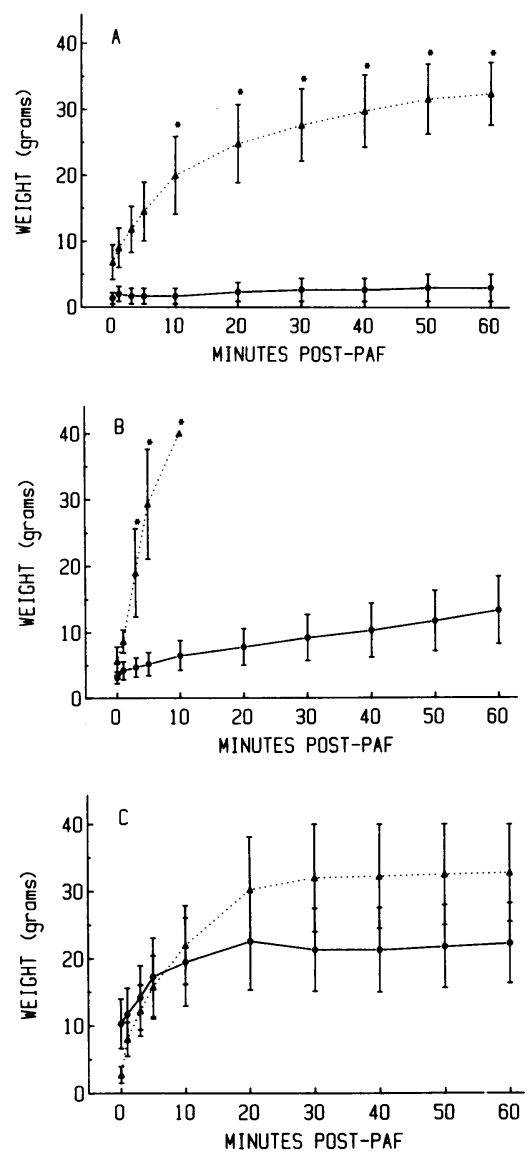

Figure 2. Effect of endotoxin on PAF-induced weight gain. Isolated rabbit lungs were perfused with LPS-free buffer (-•-) or buffer containing 100 $\mathrm{ng} / \mathrm{ml}$ of LPS

$(\cdots, \cdots)$ for $2 \mathrm{~h}$ and received PAF $1 \mathrm{nM}(A)$, $10 \mathrm{nM}(B)$, or $100 \mathrm{nM}$ (C) at time 0 . Each point represents mean \pm SEM of at least three experiments. ${ }^{*} P$ $<0.05$.
Treatment with LPS for $2 \mathrm{~h}$ markedly enhanced the development of lung edema after PAF injection. LPS potentiation of PAF-induced weight gain was most evident with the two lower concentrations of PAF examined which produced little weight gain in lungs perfused without LPS (Fig. 2). The preparations given $10 \mathrm{nM}$ PAF following LPS pretreatment developed dramatic edema, all reaching $40 \mathrm{~g}$ of weight gain within $10 \mathrm{~min}$. Treatment with $1 \mathrm{nM}$ PAF in LPS-primed lungs also induced significant weight gain compared to unprimed lungs. The net weight gain after PAF was significantly greater in lungs perfused with $100 \mathrm{ng} / \mathrm{ml}$ of LPS compared with those treated with LPS-free buffer for all three concentrations of PAF tested (Table I). These findings indicate that pretreatment with LPS markedly enhances or primes for pulmonary hypertension and edema in response to a second inflammatory mediator, PAF.

\section{Role of increased capillary permeability in LPS-primed lung edema}

The occurrence of lung edema in LPS-primed lungs led us to study the mechanisms responsible for this effect. The possible etiologies for this edema include: $(a)$ purely hydrostatic edema caused by increased microvascular pressures induced by PAF in our model which employs a buffer that lacks oncotic pressure, or $(b)$ increased capillary permeability secondary to inflammatory lung injury produced by PAF and/or LPS. To determine if increased capillary permeability contributes to pulmonary edema in our model, $K_{\mathrm{f}, \mathrm{c}}$ was measured in the IPL. The vasodilator papaverine was added to the perfusate to block increases in capillary microvascular pressure. The rate of weight change following a $5-\mathrm{mmHg}$ venous pressure challenge was measured in lungs after $2 \mathrm{~h}$ of perfusion with LPS-free or LPS $(100 \mathrm{ng} / \mathrm{ml})$ containing buffer with or without PAF $\left(10^{-8}\right)$ stimulation. The calculated $K_{\mathrm{f}, \mathrm{c}}$ values are shown in Table II. When these data were subjected to one-way ANOVA there was no significant difference in $K_{\mathrm{f}, \mathrm{c}}$ values among the four groups $(P=0.085)$. However, when two-way ANOVA was performed, examining the effects of LPS or PAF on $K_{\mathrm{f}, \mathrm{c}}$, LPS administration was found to have a significant effect $(P$ $=0.01)$ on $K_{\mathrm{f}, \mathrm{c}}$ independent of PAF $(P=1.00)$. The mean $K_{\mathrm{f}, \mathrm{c}}$ of the eight lungs given LPS (6.70) was significantly greater than lungs perfused with LPS-free buffer (1.81). These data suggest that capillary permeability is increased in the IPL after

Table II. Effect of LPS and PAF on $K_{f, c}$ in the IPL

\begin{tabular}{ccc} 
& LPS-free buffer & LPS-buffer* \\
\hline Unstimulated & $129 \pm 0.93$ & $7.20 \pm 2.48$ \\
& $(n=3)$ & $(n=3)$ \\
PAF $10^{-8} \mathrm{M}$ & $2.33 \pm 0.65$ & $6.19 \pm 1.97$ \\
& $(n=5)$ & $(n=5)$
\end{tabular}

The IPLs were perfused for $2 \mathrm{~h}$ with LPS-free or buffer containing $100 \mathrm{ng} / \mathrm{ml}$ of LPS, papaverine $0.03 \mathrm{mg} / \mathrm{ml}$ was added, and $K_{\mathrm{f}, \mathrm{c}}$ measured at $125 \mathrm{~min}$ in PAF-stimulated and unstimulated lungs after a venous pressure challenge of $5 \mathrm{mmHg}$. $K_{\mathrm{f}, \mathrm{c}}$ is calculated as weight change $(\mathrm{g} / \mathrm{s})$, per $\mathrm{mmHg}$, per gram wet lung weight $\times 10^{-4} . K_{\mathrm{f}, \mathrm{c}}$ values are mean \pm SEM.

${ }^{*} P=0.01$ when the effects on $K_{\mathrm{f}, \mathrm{c}}$ of LPS vs. LPS-free buffer were examined by two-way ANOVA. 
a 2-h exposure to $100 \mathrm{ng} / \mathrm{ml}$ of LPS and that when pulmonary hypertension is blocked, PAF has little or no effect on lung edema. The explosive edema formation of the LPS-primed, PAF-stimulated IPL probably occurs as a consequence of enhanced PAF-induced hydrostatic pressures by LPS in the presence of LPS-induced capillary permeability.

\section{Prostaglandin production in the IPL}

LPS-priming of macrophages in vitro enhances the production of arachidonic acid metabolites (18). PAF-induced injury in an isolated perfused guinea pig lung, free of platelets, has been associated with release of thromboxane and prostacyclin (19). We therefore studied the role of prostaglandins in the LPSprimed, PAF-stimulated IPL, by measuring the stable metabolites of TXA and prostacyclin.

Thromboxane. In lungs perfused with LPS-free buffer for 2 $h, 10 \mathrm{nM}$ PAF produced an increase in the amount of TXB in the perfusate (Fig. 3). Immediately before PAF administration (time 0 ) the concentration of TXB in the perfusate was $151 \pm 49 \mathrm{pg} / \mathrm{ml}$. After PAF administration, TXB levels increased rapidly to $180 \%$ of pre-PAF values at $3 \mathrm{~min}$, the earliest time point sampled, then declined rapidly. At $5 \mathrm{~min}, \mathrm{TXB}$ returned to near baseline levels ( $119 \%$ of time 0$)$ then continued to decrease below pre-PAF levels, reaching $28 \%$ of time 0 concentrations 30 min after PAF. In contrast, LPS-primed lungs had more dramatic increases and persistent elevations of TXB in the perfusate after stimulation with $10 \mathrm{nM}$ PAF (Fig. 3). 3 min after PAF administration the concentration of TXB in the perfusate rose to $264 \%$ of pre-PAF levels, however, unlike the unprimed lungs, TXB in the perfusate of LPS-treated lungs remained elevated for the duration of the experiment. These findings indicated that LPS exposure amplified both the magnitude and duration of TXB production by PAF-stimulated lungs and suggested a role for TXA or related arachidonate metabolites in the exaggerated increase in PAP that occurs in LPS-primed lungs. In fact, the time course of TXB production parallels PAP elevation in both LPS-primed and unprimed lungs stimulated with $10 \mathrm{nM}$ PAF (Fig. 4). This apparent relationship between PAP and TXB production suggests that TXA, a potent vasoconstrictor, may mediate the pulmonary hypertension produced by PAF in the rabbit IPL.

Prostacyclin. The production of $6 \mathrm{KPF}$, the stable metabolite of prostacyclin, by the IPL also increased after PAF administration. In unprimed lungs receiving $10 \mathrm{nM}$ PAF 6KPF increased to $120 \%$ of pre-PAF levels at 3 min, peaked at $149 \%$ of control at $10 \mathrm{~min}$ and remained above $130 \%$ for $30 \mathrm{~min}$ after PAF (Fig. 5). LPS-priming enhanced the production of $6 \mathrm{KPF}$

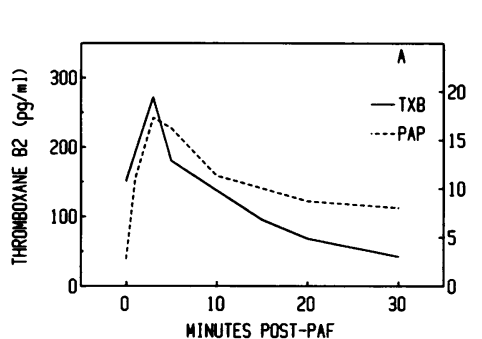

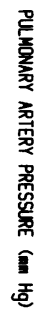

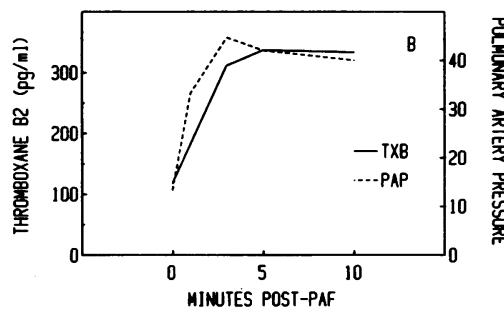

Figure 4. Comparison of the time course of pulmonary artery pressure (- - $)$ and thromboxane $\mathbf{B}_{2}$ production (-) after stimulation with $10 \mathrm{nM}$ PAF in lungs perfused with LPS-free buffer $(A)$ or buffer containing 100 $\mathrm{ng} / \mathrm{ml}$ of LPS $(B)$ for 2 $h$ prior PAF administration. Points represent mean values.

in the PAF-stimulated IPL. Unlike the rapid increase in TXB, $6 \mathrm{KPF}$ production increased gradually, reaching maximal levels (190\% of pre-PAF) 10 min after PAF. Mean levels of $6 \mathrm{KPF}$ in the perfusate of LPS-primed lungs were more than twofold higher than those in unprimed lungs at $10 \mathrm{~min}$ $(2.3 \pm 0.61 \mathrm{ng} / \mathrm{ml}$ vs. $1.13 \pm 0.29 \mathrm{ng} / \mathrm{ml})$ although these differences were not significant. These results suggest that LPSpriming also enhanced PAF-induced production of the vasodilator prostacyclin.

Effect of cyclooxygenase inhibition on LPS-priming. The temporal relationship between PAP elevation and TXB production suggested that PAF-induced production of the potent vasoconstrictor, TXA, may mediate pulmonary hypertension in the PAF-stimulated IPL, as has been suggested by others (19). This led us to examine the effect of the cyclooxygenase inhibitor indomethacin with $10 \mathrm{nM}$ PAF in our model. Thromboxane production was completely inhibited in lungs treated with $10 \mu \mathrm{M}$ indomethacin. All samples of perfusate from these lungs contained $<50 \mathrm{pg} / \mathrm{ml}$ of TXB, below the detection level of the assay, even in LPS-primed, PAF-stimulated lungs. Prostacyclin production was also markedly inhibited (Fig. 6). In indomethacin-treated lungs 6KPF levels did not increase above time 0 levels after PAF stimulation in unprimed lungs, and remained below $140 \mathrm{pg} / \mathrm{ml}$ in LPS-primed lungs. These data indicate that indomethacin treatment effectively inhibits the production of TXB and 6KPF in the PAFstimulated IPL.

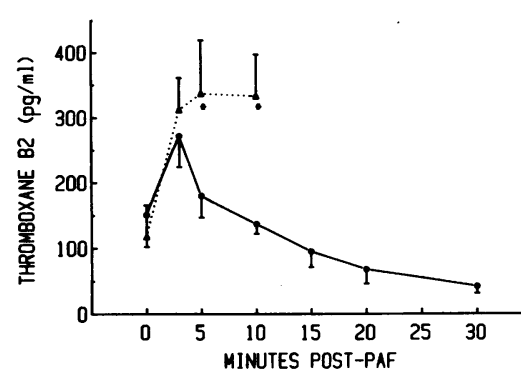

Figure 3. Thromboxane $B_{2}$ production by the PAF-stimulated isolated perfused lung, effect of LPS exposure. Lungs were perfused for $2 \mathrm{~h}$ with L.PS-free buffer (- - -), or with buffer containing $100 \mathrm{ng} / \mathrm{ml}$ of LPS (......) given 10 nM PAF at time 0. Each point represents mean \pm SEM. ${ }^{*} P<0.05$.

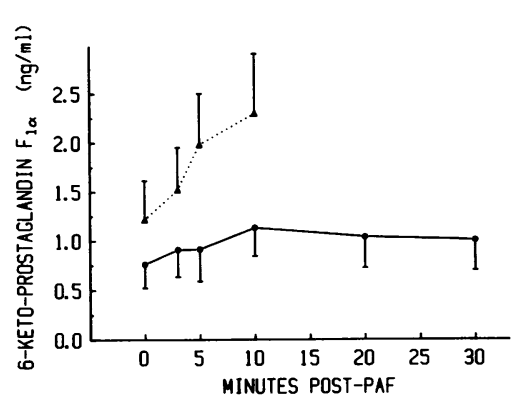

Figure 5. 6KPF production by PAF-stimulated isolated perfused lungs, effects of LPS. Lungs were perfused for $2 \mathrm{~h}$ LPS-free buffer (- - -) or with buffer containing LPS $(\cdots . \cdots)$ and given 10 nM PAF at time 0. Points represent mean \pm SEM. ${ }^{*} P<0.05$. 


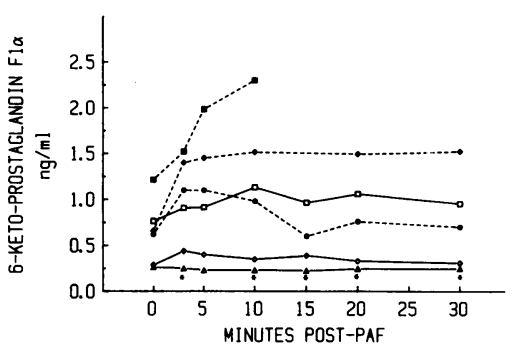

Figure 6. Effect of indomethacin, dazoxiben, and SQ 29,548 on PAFinduced $6 \mathrm{KPF}$ production. Open symbols and solid lines represent LPS-free buffer and 10 nM PAF, closed symbols and broken lines represent buffer with $100 \mathrm{ng} / \mathrm{ml}$ of LPS. $m$, no inhibitor; $\Delta$, indomethacin $10 \mu \mathrm{M} ; \bullet$, dazoxiben $5 \mu \mathrm{M}$; , SQ 29,548 $1 \mu \mathrm{M}$. 6KPF levels were undetectable $(<0.14 \mathrm{ng} / \mathrm{ml})$ in indomethacin-treated lungs receiving LPS and PAF. Points represent mean values. ${ }^{*} P<0.05$ for indomethacin-PAF vs. PAF alone.

Despite its ability to inhibit TXB production, indomethacin had very little effect on the rise in PAP produced by $10 \mathrm{nM}$ PAF in unprimed lungs. As shown in Fig. 7, PAP rose to mean peak pressure of $14 \pm 3.5 \mathrm{mmHg}$ and rapidly decreased toward normal in indomethacin-treated lungs similar to the response of untreated PAF-stimulated lungs (mean peak pressure $17.5 \pm 3.8 \mathrm{mmHg}$ ). In contrast to this, indomethacin completely inhibited the accentuated rise in PAP produced by PAF in LPS-primed lungs. The mean peak PAP produced by $10 \mathrm{nM}$ PAF in these lungs, $13.6 \pm 1.6 \mathrm{mmHg}$, was significantly less than that in LPS-primed lungs without indomethacin $(44 \pm 3$ $\mathrm{mmHg}$ ) but was similar to unprimed lungs with or without indomethacin (Fig. 7). Indomethacin treatment also prevented edema in LPS-primed lungs, while weight was unaffected in unprimed lungs (Fig. 8). These data indicate that inhibition of cyclooxygenase blocks LPS-priming of PAF-induced lung injury in the IPL suggesting that priming may be mediated through enhanced release of TXA or other prostaglandins.

Effect of specific inhibitors of thromboxane on LPS-priming. To more clearly define the role of thromboxane in the LPS-primed response, we studied the effects of an inhibitor of thromboxane synthetase, dazoxiben, and a thromboxane receptor antagonist, SQ 29,548. Dazoxiben in a concentration of $5 \mu \mathrm{M}$ blocked TXB production in response to PAF in both
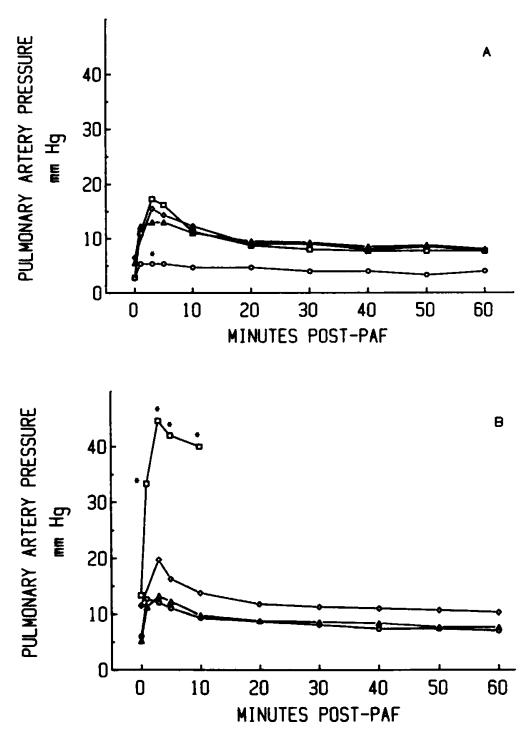

Figure 7. Effect of indomethacin, dazoxiben, and SQ 29,548 on 10 nM PAF stimulated PAP. ( $A$ ) LPS-free buffer, $(B)$ buffer containing $100 \mathrm{ng} / \mathrm{ml}$ of LPS. $\square$, no inhibitor; $\triangle$, indomethacin $10 \mu \mathrm{M}$; $\diamond$, dazoxiben $5 \mu \mathrm{M} ; \circ$, SQ 29,548 $1 \mu \mathrm{M}$. Points represent mean values of at least three experiments. $(A) * P<0.05$ for SQ 29,548 + PAF vs. PAF alone. $(B) * P$ $<0.05$ for LPS-PAF vs. all three inhibitors tested.

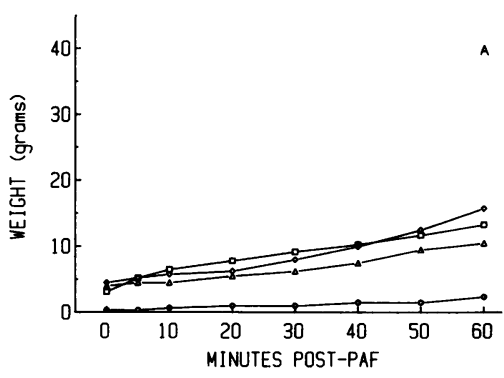

Figure 8. Effect of indomethacin, dazoxiben, and SQ 29,548 on 10 nM PAF-induced weight gain. $(A)$ LPSfree buffer; $(B)$ buffer containing $100 \mathrm{ng} / \mathrm{ml}$ LPS. $\square$, no inhibitor; $\Delta$,

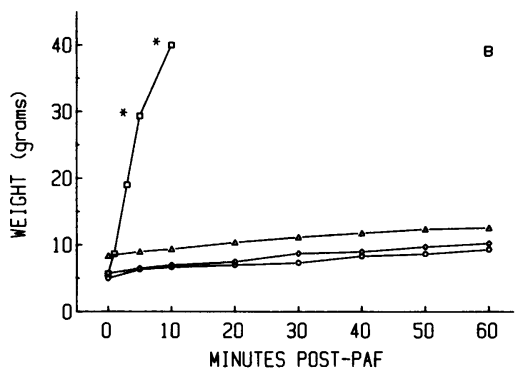
indomethacin $10 \mu \mathrm{M}$; $\diamond$, dazoxiben $5 \mu \mathrm{M} ; 0$, SQ 29,548 $1 \mu \mathrm{M}$. Points represent mean values of at least three experiments. $(A)$ No significant difference between groups. $(B){ }^{*} P<0.05$ for LPS-PAF vs. all three inhibitors tested.

LPS-primed and unprimed lungs (Fig. 9). In the presence of thromboxane synthetase blockade, the LPS-primed PAP response to PAF was completely inhibited (Fig. 7). The mean peak PAP in lungs treated with LPS, $5 \mu \mathrm{M}$ dazoxiben and 10 nM PAF was $19.8 \pm 2.1 \mathrm{mmHg}$, which was significantly less than the LPS-primed response without the inhibitor, but not different than the peak PAP in unprimed lungs stimulated with $10 \mathrm{nM}$ PAF. Dazoxiben had no effect on the PAP response to PAF in unprimed lungs. Weight gain in LPS-treated lungs was also inhibited by dazoxiben (Fig. 8).

The thromboxane receptor antagonist SQ 29,548 had similar inhibitory effects on the LPS-primed response. This compound had little effect on the levels of prostanoids in the IPL perfusates (Fig. 6, Fig. 9). Treatment with $1 \mu \mathrm{M}$ SQ 29,548 blocked the LPS-primed increment in PAP after $10 \mathrm{nM}$ PAF resulting in a mean PAP of $12.7 \pm 3.1 \mathrm{mmHg}$ (Fig. 7). Unlike the other inhibitors tested, SQ 29,548 caused significant inhibition of the mild pulmonary hypertension induced by $10 \mathrm{nM}$ PAF in unprimed lungs (mean peak PAP $5.3 \pm 3.6 \mathrm{mmHg}$ ) (Fig. 7). As with dazoxiben and indomethacin, SQ 29,548 prevented weight gain after PAF in the LPS-primed lung (Fig. 8). These data indicate that LPS-priming in the IPL is dependent upon enhanced production of thromboxane $A_{2}$ by the lung in response to PAF stimulation.

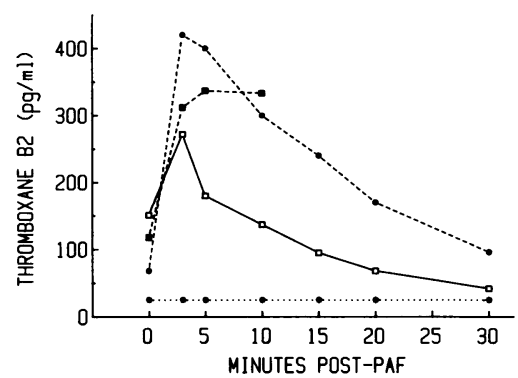

Figure 9. Effect of inhibitors on TXB production. TXB levels were undetectable $(<50$ $\mathrm{pg} / \mathrm{ml}$ ) in lungs treated with indomethacin or dazoxiben following PAF with or without LPS treatment *. Solid lines with open symbols represent LPS-free

buffer and $10 \mathrm{nM}$ PAF, broken lines with solid symbols represent LPS buffer with $10 \mathrm{nM}$ PAF. $₫$, No inhibitor; $\bullet$, SQ 29,548 $1 \mu \mathrm{M}$. Points represent mean values. 


\section{Discussion}

We have shown that the buffer-perfused rabbit lung, depleted of circulating blood cells and plasma, exhibits minimal change in weight, PAP, and production of TXB and prostacyclin after a $2-\mathrm{h}$ incubation with buffer containing $100 \mathrm{ng} / \mathrm{ml}$ of $E$. coli 0111:B4 lipopolysaccharide. However, during this 2-h exposure to LPS the lung becomes primed for an enhanced pulmonary artery pressure response, lung edema, and prostanoid production when stimulated with PAF compared to lungs perfused with LPS-free buffer. While inhibitors of cyclooxygenase, thromboxane synthetase, or thromboxane receptor blockade had little effect on PAF-stimulated, unprimed lungs, these compounds completely ablated the LPS-primed response. These findings indicate that the marked elevation of pulmonary artery pressure and secondary lung edema induced by LPS-priming is dependent upon enhanced production of TXA. Pulmonary edema in LPS-primed lungs is probably facilitated by enhanced capillary permeability induced by LPS.

The Shwartzman reaction is the classic example of hyperresponsiveness of organs and tissues to inflammatory injury following sequential administration of relatively innocuous doses of endotoxin. More recently, priming of tissues or cells for an augmented response upon stimulation with soluble agents has been described both in vitro and in vivo. Neutrophils obtained from patients with serious bacterial infections display enhanced responses when stimulated in vitro (20). Macrophages (21) or neutrophils (6) exposed to low concentrations of endotoxin in vitro produce increased amounts of superoxide anion when stimulated with a second agonist. Concentrations of soluble stimuli that fail to elicit a response may prime neutrophils (22), macrophages (23), and other cells (7) for functional responses. Thus, it appears that synergism between soluble mediators, through a process of primed-stimulation may be widely applicable in the functional responses of many cell types. The concept of priming may be significant in that the magnitude of a cellular response in the whole organism could be modulated through the action of multiple mediators.

Priming by LPS may be important in the pathogenesis of inflammatory lung injury associated with sepsis and ARDS (5). Worthen et al. (24) and Haslett et al. (25) reported that LPS potentiated acute edematous lung injury in whole rabbits given chemotactic factors intravenously. In these studies, small doses of LPS (100 ng/rabbit) given intravenously caused sequestration of PMNs in the pulmonary vasculature. Treatment with LPS plus chemotactic factors induced prolonged PMN retention in the lung and resulted in edematous lung injury in response to a second injection of chemotactic factor 6 $h$ later. A role for PMNs was proposed in that PMNs incubated with LPS in vitro were sequestered in the lung upon infusion and edematous injury did not occur in neutropenic animals. These observations suggest that LPS primes the lung for PMN-dependent injury in the whole animal through its ability to prime PMNs. In vitro studies have demonstrated that LPS primes PMNs for enhanced adhesiveness, and release of lysosomal enzymes and toxic oxygen moieties after stimulation with chemotactic factors (26).

The cell type(s) primed by LPS in our model that are responsible for the enhanced injury to PAF have not been identified. Although the buffer-perfused IPL used in our experiments was essentially devoid of circulating PMNs (containing
$<2 \mathrm{WBCs} / \mathrm{mm}^{3}$ the majority of which are mononuclear cells), electron micrographs of the buffer-perfused lungs from the IPL demonstrated a few PMNs marginated in the pulmonary vasculature (unpublished observations). Thus, we cannot entirely exclude these marginated PMNs as effector cells in our model, but the small numbers of PMNs present would argue against this possibility.

An alternate explanation is that endotoxin priming in our system may be mediated through the effects of LPS on resident cells in the lung. Mononuclear phagocytes and macrophages are profoundly affected by LPS. These cells become activated when treated with LPS and are primed for increased production of toxic oxygen radicals (21) and arachidonic acid metabolites upon stimulation with other agonists (18). LPS induces synthesis and release of tumor necrosis-alpha (TNF- $\alpha$ ), interleukin 1 (IL-1), and interferon by macrophages. TNF- $\alpha$ in particular may mediate much of the systemic toxicity produced by LPS (27).

Endotoxin also has direct effects on endothelial cells. In the presence of serum, high concentrations of LPS $(1 \mu \mathrm{g} / \mathrm{ml})$ are toxic to bovine, but not canine, goat, or human endothelial cells in culture (28). Endothelial cells cultured with LPS in the absence of serum produce IL-1 (29) and cyclooxygenase products of arachidonic acid (30) and increase expression of membrane proteins that enhance PMN adherence (31) and procoagulant activity (32). Therefore, it is possible that endothelial cells could participate in LPS-priming, either by direct effects of LPS on these cells or secondarily through the production of soluble mediators that affect other cells within the lung.

In our studies, PAF-induced pulmonary hypertension was temporally related to TXB production in both unprimed and LPS-primed lungs (Fig. 4). Inhibitors of cyclooxygenase and thromboxane synthetase blocked TXB production but had no effect on PAF-induced pulmonary hypertension in unprimed lungs, suggesting that the rise in PAP was mediated by the direct effects of PAF on the pulmonary vasculature (11). In contrast to this, the marked elevation in PAP induced by PAF in LPS-primed lungs was completely blocked by inhibitors of TXB production or receptor binding. In LPS-primed lungs treated with these inhibitors, PAF elicited a rise in PAP that was indistinguishable from that seen in unprimed lungs. These findings suggest that TXA production is necessary to induce enhanced pulmonary hypertension observed in LPS-primed lungs.

Hamaski et al. found that PAF induced TXB production, pulmonary hypertension, and edema in the cell-free, buffer perfused guinea pig IPL, all of which were inhibited by indomethacin (19). TXB release by PAF-stimulated IPL and parenchymal lung strips of guinea pigs is blocked by the PAF-receptor antagonist BN 52021, suggesting that PAF itself directly stimulates TXA production in responsive cells (33). The cell type responsible for TXB production in the lung has not been identified. In the whole animal or in the presence of blood, platelets are clearly the major source of thromboxane (34). The lungs in our experiments and others (19) are platelet free. Using mouse peritoneal macrophages, Aderem et al. found that low concentrations of LPS $(10 \mathrm{ng} / \mathrm{ml})$ primed for enhanced release of arachidonic acid upon stimulation with particulate (zymosan or IgG-coated beads) or soluble (phorbol myristate acetate or A23187) stimuli $(18,35)$. However, thromboxane release by these LPS-primed cells was not reported; the major cyclooxygenase products measured were 
$\mathrm{PGE}_{2}$ and prostacyclin. TXB is produced in rat peritoneal macrophages stimulated with high concentrations $(50 \mu \mathrm{g} / \mathrm{ml})$ of LPS alone (36) and in human monocytes by $10 \mu \mathrm{g} / \mathrm{ml}$ of LPS (37). PAF-stimulated guinea pig peritoneal macrophages produce TXB as well (38). Endothelial cells also produce prostaglandins in response to LPS but in bovine and sheep cells these are predominantly $\mathrm{PGE}_{2}$ and prostacyclin (30), while equine cells produce small amounts of TXB in response to high concentrations $(10 \mu \mathrm{g} / \mathrm{ml})$ of LPS (39). In contrast, stimulation of bovine endothelial cells with the calcium ionophore A23187 induces significant TXB release (40). In addition, rabbit pulmonary artery strips produce TXB in response to exogenous arachidonic acid (41). Other connective tissue cells in the lung could also be involved. Vascular smooth muscle cells produce prostaglandins (12), while cultured human lung fibroblasts have the capacity to synthesize TXB (42). Thus in our model, any one of several cell types may be the source of the enhanced TXB release that follows primed stimulation. In preliminary studies, we do not detect amplified production of TXB by rabbit alveolar macrophages obtained from LPSprimed IPLs upon in vitro stimulation of these cells with PAF (unpublished observations).

Another question raised by our studies is the nature of the subcellular mechanisms involved in LPS-priming. LPS induces phosphoinositol turnover and protein kinase $C$ activation (43) in macrophages, mechanisms that may mediate the primed response in other cell systems (7). Phospholipase $A_{2}$ $\left(\mathrm{PLA}_{2}\right)$, a calcium-dependent enzyme that cleaves arachidonic acid from membrane phospholipids, is increased in the lungs of rats given LPS in vivo (44). It is conceivable that increased levels of cytosolic calcium induced by PAF in the presence of enhanced $\mathrm{PLA}_{2}$ activity could augment the release of arachidonate in responsive cells. Another possible mechanism of LPS priming could be through increased synthesis and/or activation of the enzymes of the cyclooxygenase pathway or TXA synthetase itself. Recently, Frazier-Scott et al. showed that interleukin 2 induces the synthesis of prostaglandin $\mathbf{H}$ synthetase in human and bovine endothelial cells (45). A similar enhancement of prostaglandin $\mathrm{H}$ synthetase activity might be induced by LPS itself or LPS-induced cytokines in our model, explaining the increased production of $6 \mathrm{KPF}$ as well as TXB. Our finding of enhancement of both TXB and 6KPF levels suggests that a proximal step in the cyclooxygenase pathway such as increased availability of arachidonic acid may be the rate-limiting step.

Macrophages stimulated with LPS produce large amounts of the proinflammatory cytokines TNF- $\alpha$ and IL-1. In addition IL- 1 is produced by TNF- $\alpha$ or LPS-stimulated endothelial cells (29) and by fibroblasts in response to TNF- $\alpha$ (46). TNF- $\alpha$ in particular may mediate many of the adverse systemic effects of LPS in sepsis syndromes (27) and the combination of IL-1 and TNF- $\alpha$ may synergistically induce inflammatory injury (47). Induction of these protein mediators could play a role in LPS-priming through their ability to directly stimulate prostanoid production (48) or by priming inflammatory cells. We are now attempting to determine if the rabbit IPL produces TNF- $\alpha$ during LPS-priming and if so whether TNF- $\alpha$ production is necessary for LPS-primed, PAF-stimulated thromboxane release.

In our studies we found that LPS exposure caused a signifcant increase in capillary permeability in the IPL while PAF had little effect in the presence of the vasodilator papaverine. These data indicate another potentially important aspect of
LPS-priming, and provide an explanation for the pulmonary edema associated with the primed response. LPS-induced increases in capillary permeability would allow rapid extravasation of edema fluid in response to increased microvascular hydrostatic forces that follow enhanced release of TXA. A similar sequence of events could occur in human (2) or animal models (9) of septic lung injury in which pulmonary hypertension, increased TXA production, and diffuse capillary leak are common early manifestations of ARDS.

In summary, our findings indicate that LPS primes the isolated perfused rabbit lung for enhanced pulmonary hypertension and edema in response to the physiologic mediator PAF. This primed-stimulation response requires enhanced production of TXA. The underlying mechanisms responsible for LPS-priming and the cells responding to primed-stimulation in the lung are currently under investigation. A better understanding of this phenomenon may provide insight into the pathogenic mechanisms involved when multiple mediators interact to induce severe inflammatory injury states such as septic shock and the adult respiratory distress syndrome.

\section{Acknowledgments}

The authors thank Clifford Hubbard and Joanna Bowman for their expert technical assistance and Gina Collins for secretarial assistance.

This work was supported by grants from the National Institutes of Health Heart, Lung, and Blood Institute, K08 HL-01634 and HL-29293.

\section{References}

1. Tomashefski, J. F., P. Davies, C. Boggis, R. Greene, W. M. Zapol, and L. M. Reid. 1983. The pulmonary vascular lesions of the adult respiratory distress syndrome. Am. J. Pathol. 112:112-126.

2. Rinaldo, J. E., and R. M. Rogers. 1982. Adult respiratory-distress syndrome. Changing concepts of lung injury and repair. N. Engl. J. Med. 306:900-909.

3. Emancipator, S. N., and M. E. Lamm. 1986. Pathways of tissue injury initiated by humoral immune mechanisms. Lab. Invest. $54: 475-478$.

4. Lundberg, C., F. Marceau, and T. E. Hugli. 1987. C5a-induced hemodynamic and hematologic changes in the rabbit. Role of cyclooxygenase products and polymorphonuclear leukocytes. Am. J. Pathol. 128:471-483.

5. Cochrane, C. G. 1987. The enhancement of inflammatory injury. Am. Rev. Respir. Dis. 136:1-2.

6. Guthrie, L. A., L. C. McPhail, P. M. Henson, and R. B. Johnston. 1984. Priming of neutrophils for enhanced release of oxygen metabolites by bacterial lipopolysaccharide. Evidence for increased activity of the superoxide-producing enzyme. J. Exp. Med. 160:16561671 .

7. Alkon, D. L., and H. Rasmussen. 1988. A spatial-temporal model of cell activation. Science (Wash. DC). 239:998-1005.

8. Pepe, P. E., R. T. Potkin, D. H. Reus, L. D. Hudson, and C. J. Carrico. 1982. Clinical predictors of the adult respiratory distress syndrome. Am. J. Surg. 144:124-130.

9. Olson, N. C., W. L. Salzer, and C. E. McCall. 1988. Biochemical, physiological, and clinical aspects of endotoxemia. Mol. Aspects Med. 10:511-629.

10. Brigham, K. L., and B. Meyrick. 1986. Endotoxin and lung injury. Am. Rev. Respir. Dis. 133:913-927.

11. Braquet, P., L. Touqui, T. Y. Shen, and B. B. Vargaftig. 1987. Perspectives in platelet-activating factor research. Pharmacol. Rev. 39:97-145.

12. Smith, W. L. 1986. Prostaglandin biosynthesis and its compartmentation in vascular smooth muscle and endothelial cells. Annu. Rev. Physiol. 48:251-262. 
13. Chang, S-W., C. O. Fedderson, P. M. Henson, and N. F. Voelkel. 1987. Platelet-activating factor mediates hemodynamic changes and lung injury in endotoxin-treated rats. J. Clin. Invest. 79:14981509.

14. Shasby, D. M., K. M. Vanbenthuysen, R. M. Tate, S. S. Shasby, I. McMurtry, and J. E. Repine. 1982. Granulocytes mediate acute edematous lung injury in rabbits and in isolated rabbit lungs perfused with phorbol myristate acetate: Role of oxygen radicals. Am. Rev. Respir. Dis. 125:443-447.

15. Surles, J. R., R. L. Wykle, J. T. O'Flaherty, W. L. Salzer, M. J. Thomas, F. Snyder, and C. Piantadosi. 1985. Facile synthesis of platelet-activating factor and racemic analogues containing unsaturation in the sn-1-alkyl chain. J. Med. Chem. 28:73-78.

16. Seeger, W., D. Walmrath, M. Menger, and H. Neuhof. 1986. Increased lung vascular permeability after arachidonic acid and hydrostatic challenge. J. Appl. Physiol. 61:1781-1789.

17. McMurtry, I. F., and K. G. Morris. 1986. Platelet-activating factor causes pulmonary vasodilation in the rat. Am. Rev. Respir. Dis. 134:757-762.

18. Aderem, A. A., D. S. Cohen, S. D. Wright, and Z. A. Cohn. 1986. Bacterial lipopolysaccharides prime macrophages for enhanced release of arachidonic acid metabolites. J. Exp. Med. 164:165-179.

19. Hamasaki, Y., M. Mojarad, T. Saga, H.-H. Tai, and S. I. Said. 1984. Platelet-activating factor raises airway and vascular pressures and induces edema in lungs perfused with platelet-free solution. Am. Rev. Respir. Dis. 129:742-746.

20. McCall, C. E., L. R. DeChatelet, M. R. Cooper, and C. Shannon. 1973. Human toxic neutrophils. III. Metabolic characteristics. $J$. Infect. Dis. 127:26-33.

21. Pabst, M. J., and R. B. Johnston. 1980. Increased production of superoxide by macrophages exposed in vitro to muramyl dipeptide or lipopolysaccharide. J. Exp. Med. 151:101-114.

22. Bass, D. A., C. Gerard, P. Olbrantz, J. Wilson, C. E. McCall, and L. C. McPhail. 1987. Priming of the respiratory burst of neutrophils by diacylglycerol. Independence from activation or translocation of protein kinase C. J. Biol. Chem. 262:6643-6649.

23. Finkel, T. H., M. J. Pabst, H. Suzuki, L. A. Guthrie, J. R. Forehand, W. A. Phillips, and R. B. Johnston. 1987. Priming of neutrophils and macrophages for enhanced release of superoxide anion by the calcium ionophore ionomycin. Implications for regulation of the respiratory burst. J. Biol. Chem. 262:12589-12596.

24. Worthen, G. S., C. Haslett, A. J. Rees, R. S. Gumbay, J. E. Henson, and P. M. Henson. 1987. Neutrophil-mediated pulmonary vascular injury. Synergistic effect of trace amounts of lipopolysaccharide and neutrophil stimuli on vascular permeability and neutrophil sequestration in the lung. Am. Rev. Respir. Dis. 136:19-28.

25. Haslett, C., G. S. Worthen, P. C. Giclas, D. C. Morrison, J. E. Henson, and P. M. Henson. 1987. The pulmonary vascular sequestration of neutrophils in endotoxemia is initiated by an effect of endotoxin on the neutrophil in the rabbit. Am. Rev. Respir. Dis. 136:9-18.

26. Haslett, C., L. A. Guthrie, M. M. Kopaniak, R. B. Johnston, and P. M. Henson. 1985. Modulation of multiple neutrophil functions by preparative methods or trace concentrations of bacterial lipopolysaccharide. Am. J. Pathol. 119:101-110.

27. Beutler, B., I. W. Milsark, and A. C. Cerami. 1985. Passive immunization against cachectin/tumor necrosis factor protects mice from the lethal effects of endotoxin. Science (Wash. DC). 229:869871.

28. Harlan, J. M., L. A. Harker, M. A. Reidy, C. M. Gajdusek, S. M. Schwartz, and G. E. Striker. 1983. Lipopolysaccharide-mediated bovine endothelial cell injury in vitro. Lab. Invest. 48:269-274.

29. Libby, P., J. M. Ordovas, K. R. Auger, A. H. Robbins, L. K. Birinyi, and C. A. Dinarello. 1986. Endotoxin and tumor necrosis factor induce interleukin 1 gene expression in adult human vascular endothelial cells. Am. J. Pathol. 124:179-185.

30. Meyrick, B., R. Hoover, M. R. Jones, L. C. Berry, and K. L. Brigham. 1989. In vitro effects of endotoxin on bovine and sheep lung microvascular and pulmonary artery endothelial cells. J. Cell. Physiol. 138:165-174.

31. Schleimer, R. P., and B. K. Rutledge. 1986. Cultured human vascular endothelial cells acquire adhesiveness for neutrophils after stimulation with interleukin 1, endotoxin, and tumor-promoting phorbol diesters. J. Immunol. 136:649-654.

32. Moore, K. L., S. P. Andreoli, N. L. Esmon, C. T. Esmon, and N. U. Bang. 1987. Endotoxin enhances tissue factor and suppresses thrombomodulin expression of human vascular endothelium in vitro. J. Clin. Invest. 79:124-130.

33. Desquand, S., C. Touvay, J. Randon, V. Lagente, B. Vilain, I. Maridonneau-Parini, A. Etienne, J. Lefort, P. Braquet, and B. B. Vargaftig. 1986. Interference of BN 52021 (ginkolide B) with the bronchopulmonary effects of PAF-acether in the guinea-pig. Eur. J. Pharmacol. 127:83-95.

34. Oates, J. A., G. A. Fitzgerald, R. A. Branch, E. K. Jackson, H. R. Knapp, and L. J. Roberts. 1988. Clinical implications of prostaglandin and thromboxane $\mathrm{A}_{2}$ formation. N. Eng. J. Med. 319:689698, 761-767.

35. Aderem, A. A., and Z. A. Cohn. 1988. Calcium ionophore synergizes with bacterial lipopolysaccharide in activating macrophage arachidonic acid metabolism. J. Exp. Med. 167:623-631.

36. Cook, J. A., W. C. Wise, and P. V. Halushka. 1981. Thromboxane $A_{2}$ and prostacyclin production by lipopolysaccharide-stimulated peritoneal macrophages. J. Reticuloendothel. Soc. 30:445-450.

37. Nichols, F. C., H. A. Schenkein, and R. B. Rutherford. 1987. Prostaglandin $E_{2}$, prostaglandin $E_{1}$, and thromboxane $B_{2}$ release from human monocytes treated with $\mathrm{C} 3 \mathrm{~b}$ or bacterial lipopolysaccharide. Biochim. Biophys. Acta. 927:149-157.

38. Hartung, H-P. 1983. Acetyl glyceryl ether phosphorylcholine (platelet-activating factor) mediates heightened metabolic activity in macrophages. Studies on $\mathrm{PGE}, \mathrm{TXB}_{2}$, and $\mathrm{O}_{2}^{-}$production, spreading, and the influence of calmodulin-inhibitor W-7. FEBS (Fed. Eur. Biochem. Soc.) Lett. 160:209-212.

39. Bottoms, G. D., M. A. Johnson, C. H. Lamar, J. F. Fessler, and J. J. Turek. 1985. Endotoxin-induced eicosanoid production by equine vascular endothelial cells and neutrophils. Circ. Shock. 15:155-162.

40. Ingerman-Wojenski, C., M. J. Silver, J. B. Smith, and E. Macarak. 1981. Bovine endothelial cells in culture produce thromboxane as well as prostacyclin. J. Clin. Invest. 67:1292-1296.

41. Salzman, P. M., J. A. Salmon, and S. Moncada. 1980. Prostacyclin and thromboxane $A_{2}$ synthesis by rabbit pulmonary artery. $J$. Pharmacol. Exp. Ther. 215:240-247.

42. Bryant, R. W., S. J. Feinmark, A. N. Makheja, and J. M. Bailey. 1978. Lipid metabolism in cultured cells. Synthesis of vasoactive thromboxane $A_{2}$ from $\left[{ }^{14} \mathrm{C}\right]$ arachidonic acid by cultured lung fibroblasts. J. Biol. Chem. 253:8134-8142.

43. Wightman, P. D., and C. R. Raetz. 1984. The activation of protein kinase $\mathrm{C}$ by biologically active moieties of lipopolysaccharide. J. Biol. Chem. 259:10048-10052.

44. Von Wichert, P., M. Temmesfeld, and W. Meyer. 1981. Influence of septic shock upon phosphotidylcholine remodeling mechanisms in rat lung. Biochim. Biophys. Acta. 664:487-497.

45. Frasier-Scott, K., H. Hatzakis, D. Seong, C. M. Jones, and K. K. Wu. 1988. Influence of natural and recombinant interleukin 2 on endothelial cell arachidonate metabolism. Induction of de novo synthesis of prostaglandin H synthetase. J. Clin. Invest. 82:1877-1883.

46. Le, J., D. Weinstein, U. Gubler, and J. Vilcek. 1987. Induction of membrane-associated interleukin 1 by tumor necrosis factor in human fibroblasts. J. Immunol. 138:2137-2142.

47. Movat, H. Z., C. E. Burrowes, M. I. Cybulsky, and C. A. Dinarello. 1987. Acute inflammation and a Shwartzman-like reaction induced by interleukin-1 and tumor necrosis factor. Synergistic action of the cytokines in the induction of inflammation and microvascular injury. Am. J. Pathol. 129:463-476.

48. Kawakami, M., S. Ishibashi, H. Ogawa, T. Murase, F. Takaku, and S. Shibata. 1986. Cachectin/TNF as well as interleukin-1 induces prostacyclin synthesis in cultured vascular endothelial cells. Biochem. Biophys. Res. Commun. 141:482-487. 